\title{
O DEBATE PSICOLÓGICO E FILOSÓFICO SOBRE A TEORIA DO RECONHECIMENTO NA VISÃO DE AXEL HONNETH: O QUE TORNA UMA PESSOA FELIZ
}

\author{
Andréa Costa de Andrade ${ }^{1}$
}

RESUMO: O debate psicológico sobre a teoria do reconhecimento adquire relevância significativa na atualidade, uma vez que ser reconhecido para o indivíduo quer seja socialmente, politicamente ou culturalmente, relaciona-se a procura pelo respeito e pela autonomia. Em torno desse debate, a Psicologia, por meio do estudo da subjetividade e a Filosofia por meio do pensamento ético-político quanto ao conceito de reconhecimento encontra na teoria crítica do filósofo e sociólogo Axel Honneth uma forma de elucidar a relação existente entre subjetividade e intersubjetividade. $O$ objetivo deste artigo foi compreender o pensamento ético-político dos aspectos filosóficos de Axel Honneth sobre a teoria do reconhecimento, estabelecendo um percurso filosóficopsicológico quanto à importância de tornar uma pessoa feliz. A meta final foi incursionar conhecimentos sobre o tema reconhecimento nas teorias de Hegel e Axel Honneth; diferenciar a subjetividade filosófica e psicológica quanto ao tema reconhecimento; refletir sobre as questões da intersubjetividade na problemática do reconhecimento na Filosofia e na Psicologia e; identificar as relações entre o reconhecimento e a felicidade. Como recurso metodológico, presentifica-se a Fenomenologia de Martin Buber e do Espírito de Hegel estabelecendo um verdadeiro tratado sobre o reconhecimento que vem a defender conceitos como: moralidade, eticidade e da subjetividade, em conjunto a psicanálise lacaniana. A finalidade é construir uma compreensão do reconhecimento por meio das ideias filosóficas, conceitos psicológicos e dos argumentos críticos que Honneth desenvolvem uma trajetória e um arcabouço argumentativo em torno da temática do reconhecimento e sobre o que torna uma pessoa feliz permitindo apresentar críticas às ideias de outros filósofos ao falar sobre o tema reconhecimento.

Palavras-chave: Teoria do Reconhecimento. Subjetividade. Psicologia. Filosofia.

ABSTRACT: The psychological discussion about of recognition theory acquires significant relevance today, since being recognized for the individual, whether socially, politically or culturally, is related to the search for respect and autonomy. Around this debate, Psychology, through the study of subjectivity and Philosophy through ethical-political thinking regarding the concept of recognition, finds in the critical theory of philosopher and sociologist Axel

${ }^{\mathrm{I}}$ Psicóloga da Fundação Hospital Adriano Jorge (FHAJ) e do Hospital Universitário Getúlio Vargas (HUGV/UFAM). Doutora em Sociedade e Cultura da Amazônia pela Universidade Federal do Amazonas (UFAM). Pós-Doctoranda en Psicología con Orientación en Metodología de la Investigación por la Universidad de Flores (UFLO).E-mail: andrea.andradeıı@gmail.com. 
Honneth a way to elucidate the relationship between subjectivity and intersubjectivity. The objective of this article was to understand the ethical-political thinking of the philosophical aspects of Axel Honneth on the theory of recognition, establishing a philosophicalpsychological path regarding the importance of making a person happy. The final goal was to incur knowledge on the topic of recognition in the theories of Hegel and Axel Honneth; to differentiate philosophical and psychological subjectivity on the topic of recognition; reflect on the issues of intersubjectivity in the problem of recognition in Philosophy and Psychology and; identify the relationships between recognition and happiness. As a methodological resource, the Phenomenology of Martin Buber and the Spirit of Hegel is presented, establishing a true treaty on recognition that defends concepts such as: morality, ethics and subjectivity, together with Lacanian psychoanalysis. The purpose is to build an understanding of recognition through philosophical ideas, psychological concepts and critical arguments that Honneth develop a trajectory and an argumentative framework around the theme of recognition and what makes a person happy, allowing criticizing the ideas of others philosophers when talking about the topic of recognition.

Keywords: Theory of Recognition. Subjectivity. Psychology. Philosophy.

\section{INTRODUÇÃO}

O conceito sócio-filosófico sobre o reconhecimento (anerkennung) transpõe o sentido de percepção cognitiva quando aborda o tema como uma necessidade de obter respeito nas relações intersubjetivas, as quais de acordo com Martin Buber (1878-1965), dizem respeito à capacidade de relacionamento do ser humano com o seu semelhante pela troca de subjetividades. A intersubjetividade circunda, portanto, o mundo da vida do ser humano e por isso, precisa ser refletida e analisada pela psicologia, considerando uma abordagem cognitiva, fenomenológica e existencial e pela filosofia, em especial, pelo pensamento ético, políticofilosófico.

A relação entre o eu e o tu envolve o diálogo, o encontro e a responsabilidade entre dois sujeitos, ou ainda, entre o sujeito e o objeto, pois,

A palavra princípio Eu-Tu fundamenta-se um modo de se aproximar do mundo diferente do da experiência: é o mundo da relação que abrange, perpassa e significa as diversas esferas da vida do homem: a vida com a natureza, a vida com os homens e a vida com os seres espirituais (BUBER, 200I, p. 55).

O conceito de reconhecimento originou-se filosoficamente na obra de Georg W.

F. Hegel (1770-1831), filósofo alemão que caracteriza o "reconhecimento" como uma forma de auto-reconhecimento e de reconhecimento pelo outro. Esse reconhecimento seria intersubjetivo e alcançado por meio de lutas. A ideia chave para a Teoria do Reconhecimento 


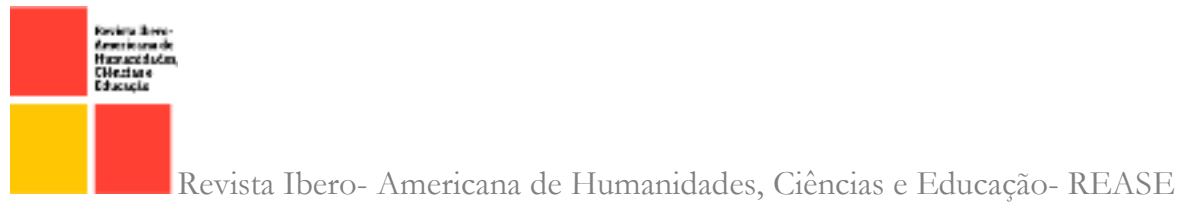

é a de relação, pois é no encontro com o outro que as identidades se constroem e que de certa forma, alçaria vôo por meio da auto-realização.

$\mathrm{Na}$ contemporaneidade, Charles Taylor (nascido em 1931) e Axel Honneth (nascido em 1949) são os dois dos principais autores que retomam a definição de "reconhecimento" estabelecida por Hegel e a reformulam, adaptando-a para a realidade social vigente. A ideia do reconhecimento adquire uma relevância significativa, uma vez que ser reconhecido é obter reconhecimento social, político, cultural, aspectos que tornam-se importantes e podem tornar uma pessoa feliz.

Envolta nessas ideais, a Filosofia nos estudos sobre o pensamento ético-político vem elaborando algumas reflexões que convergem e divergem sobre o conceito de reconhecimento. Aqui, se destacam as ideias de Axel Honneth, filósofo e sociólogo alemão, atual diretor do Instituto de Pesquisa Social e Crítica de Frankfurt.

O pensamento político de Axel Honneth encontra na teoria crítica, a filosofia do reconhecimento, que em primeiro lugar, perpassa que a relação existente entre subjetividade e intersubjetividade no pensamento psicológico e filosófico que influi nessa temática. Em segundo lugar a Fenomenologia do Espírito de Hegel é um verdadeiro tratado sobre o reconhecimento. Em terceiro lugar, os argumentos críticos desenvolvidos por Honneth associam-se e atualizam-se diante do pensamento de Hegel e outros estudiosos sobre o reconhecimento.

Dentre estas atualidades, frisa-se a luta das sociedades indígenas que procuram o respeito pela autonomia, que é de suma importância para o ser humano. As sociedades indígenas do Brasil e na América Latina comungam suas lutas por reconhecimento se contrapõem as formas de desprezo nos processos de urbanização e migração dos povos latinoamericanos, que incluem os povos da Amazônia. Outra problemática, que pode ser citada, relaciona-se as formas de desprezo aos nortistas no Brasil e suas lutas por reconhecimento.

Dito de outro modo se faz importante construir um alicerce argumentativo que seja capaz de pensar sobre as relações entre o reconhecimento versus o desprezo, pois é nessa dialética que subsiste a arquitetura dessas relações entre povos, culturas, direito e democracia. Afinal, uma reflexão sobre a ideia do reconhecimento implica em ideias como: liberdade, respeito e comunicação entre os seres humanos provendo assim, diversas inflexões 
de pensamentos e contextos culturais.

É interessante perceber que no circuito da teoria do reconhecimento, tanto existe uma possibilidade emancipatória, quanto de uma reprodução cultural. As instituições socias, por exemplo, nas quais o indivíduo é educado, influem na constituição da personalidade do ser, fato que se refletirá nos processos de subjetivação. No mundo da vida, como diria Habermas (2003) vigora a racionalidade comunicativa, que permitirá a emancipação ser. O mundo da vida é um espaço de potencial emancipatório, com as estruturas próprias da ação comunicativa, que se opoe ao sistema (colonização). O mundo da vida permite evidenciar a importância de uma visão existencialista que se caracteriza pela inclusão do indivíduo na realidade concreta, ou seja, em sua mundanidade, angústia, morte etc.

No centro da especulação filosófica "encontra-se uma polêmica com doutrinas racionalistas que dissolvem a subjetividade individual em sistemas conceituais abstratos e universalistas" (MAINGUENEAU, 2014, p.45).

A subjetividade produz, portanto, um sentido às coisas e muitas vezes o intérprete,

Não se dá conta de que o fundamento permanente de seu trabalho mental, subjetivo, é o mundo circundante vital que constantemente é pressuposto como base, como terreno da atividade, sobre o qual suas perguntas e seus métodos de pensar adquirem um sentido (HUSSERL, 2002, p. 90).

Por outro lado, persiste a ideia de intersubjetividade que diz respeito à relação entre sujeitos e entre sujeito e objeto. O relacionamento entre indivíduos no ambiente localiza-se no campo da ação e na liberdade de ação, o que implica na negociação com o outro. A intersubjetividade ou o entrecruzamento de significantes são marcas impressas no aparelho psíquico e produz efeitos de significação que podem revelar a posição subjetiva do sujeito. O significante, por sua vez, funcionará como o ordenador que gera sentido e significação (LACAN, 1979).

Nesse compasso é justificável que um dos referenciais teóricos de Honneth, com suas preocupações com o desenvolvimento de uma intersubjetividade que busca a preservação do "desenvolvimento do indivíduo, do singular" (HONNETH, 2003, p.r7). Para Honneth (2003) estaria presente à ideia 
de conflito e de desrespeito social, de ataque à identidade pessoal e coletiva, ou seja, a reconstrução da lógica dessas experiências do desrespeito e do desencadeamento da luta em sua diversidade se articula por meio da análise da formação da identidade prática do indivíduo com um contexto prévio de relações de conhecimento.

A leitura de Honneth (2003) possibilita entender a luta por reconhecimento como um ganho de contornos de um conflito social. Segundo ele, "uma tensão moral pode suscitar movimentos sociais, o que não faltaria às formas de desrespeito como a privação de direitos e a degradação de formas de vida, ligadas respectivamente às esferas do direito e da estima social” (HONNETH, 2003, p. I8).

Nessa perspectiva surgem três formas de reconhecimento: amor, direito e estima as quais corresponderão, também, às formas respectivas de desrespeito. É "por meio do reconhecimento intersubjetivo que os sujeitos podem garantir a plena realização de suas capacidades e uma autorrelação íntegra, uma vez que as identidades são construídas relacionalmente" (IBIDEM, 2003).

A grande questão dessa discussão reside nas perspectivas da luta por reconhecimento e sua presentificação no mundo da vida. Abordar a ideia original de Hegel e a constituição, por meio da experiência, de ser reconhecido e não se ver reconhecido de uma maneira satisfatória, quando da análise do reconhecimento mútuo, é fundamental, pois a vida social e as formas de reconhecimento possam representar uma espécie de base intersubjetiva que obriga cada sujeito a tratar todos os outros, segundo as suas próprias pretensões legítimas; pois, diferentemente do amor e da estima, o direito representa uma forma de reconhecimento recíproco que não admite estruturalmente uma limitação ao domínio particular das relações sociais próximas e interfere na ideia de socialiabilização dialogada.

Todavia, o mero princípio da relação entre os humanos não oferece nenhuma base adequada, visto que, enquanto tal, ela deixa totalmente indefinido quais direitos o sujeito de fato dispõe em particular. No ponto de interseção do serreconhecido abstrato, os processos de formação individual de todos os membros da 
sociedade acabam coincidindo fazendo permanecer em aberto o modo pelo qual as pessoas necessitam do reconhecimento recíproco (MELO, 2013). Por essa razão, a Filosofia do Espírito de Hegel afirma que,

\begin{abstract}
A construção da realidade social como processo de formação através da qual a relação abstrata de reconhecimento jurídico se amplia pouco a pouco, abarcando conteúdos materiais; que procede da acumulação de formas sempre novas de concretização da relação jurídica (MENDONÇA, 2009, p.96).
\end{abstract}

A proposta de Axel Honneth, em particular, na obra Luta por reconhecimento, publicada em 1992 e reelaborada em 2003, estabelece uma revisão especial quanto à parte em que cuida das influências da Filosofia hegeliana quanto a sua teoria do reconhecimento, aprofundando conhecimentos sobre as questões da Psicologia, incluindo diálogos mais pertinenetes sobre a temática.

Para compreender os aspectos psicológicos das filosofias de Hegel até Axel Honneth sobre a teoria do reconhecimento e sua importância no tornar uma pessoa feliz é necessário incursionar conhecimentos que diferenciam a subjetividade filosófica e da psicológica, bem como; refletir sobre as questões da intersubjetividade na problemática do reconhecimento tanto na Filosofia e quanto na Psicologia e; identificar as relações entre o reconhecimento e a felicidade.

As alterações na obra mais atualizada de Honneth foram realizadas com o intuito de revisitar os pontos de influência do jovem Hegel. Observa-se que se trata de uma abordagem mais intensa a partir da psicologia social que se faz compreender via o caminho percorrido pela teoria do reconhecimento a partir dos aspectos da obra, a Luta por Reconhecimento (2003), a qual propicia uma sistematização para o entendimento do pensamento estratégico para a teoria do reconhecimento.

A intenção de Honneth foi facilitar à luz da teoria crítica à compreensão sobre a luta por reconhecimento. Honneth compõe a terceira geração dos estudiosos sobre Teoria Crítica. Foi, ainda, assistente de Habermas, teórico da comunicação, na Escola de Frankfurt, tendo em maio de 20oI, assumido a direção do Instituto de Pesquisa Social da mesma Escola.

No curso de sua trajetória, Honneth passa a acreditar que o simples 
alargamento do conceito de racionalidade e da respectiva ação social não seria suficiente para dar conta de uma crítica de natureza emancipatória. Inclui, então, as ideias de Theodor W. Adorno (1903-1969) e Max Horkheimer (1895-1973) para aprimorar as ideias sobre o reconhecimento. $O$ alargamento desses conceitos encontra-se nas diretrizes da Teoria Crítica, tendo em vista que na realidade, existiria um déficit da teoria crítica no que concerne à ação política. Portanto, tendo focado sempre na questão filosófica, para Honneth, o problema da Teoria Crítica seria a falta de uma base mais sociológica para fundamentar a ação política, ocasionando um déficit de natureza sociológica.

\section{A TEORIA DO RECONHECIMENTO E AS TEMÁTICAS CONTEMPORÂNEAS}

As leituras das obras de Axel Honneth sobre a teoria do reconhecimento configuram-se temáticas contemporâneas e de polêmicas discussões. O reconhecimento é uma ação que distingue sujeitos, sujeito-objetivo e objetos e provavelmente, deve utilizar a análise das características próprias da pessoa e do objeto. Quando se reconhece, faz-se uma individualização ou identificação e, quando se é reconhecido, se é individualizado e diferenciado dos demais. O reconhecimento, nesse sentido, pode ser um ato de distinção que expressa uma honra ao mérito.

Analisar a problemática do reconhecimento é uma preocupação que remete as questões acerca do relacionamento do eu consigo próprio e do eu com o outro. Nesse sentido, a Filosofia de Hegel desempenhou um papel central ao estabelecer os termos nucleares em que esse tema é, ainda hoje, pensado, chamando a atenção para a natureza intersubjetiva da consciência.

$\mathrm{Na}$ perspectiva filosófica contemporânea, Honneth (2003) propõe discussões sobre o reconhecimento que introduzem o multiculturalismo, os conflitos culturais e religiosos, a ética e justiça social, a identidade e a intersubjetividade. Desse modo, a necessidade do homem de sentir-se reconhecido e de ser valorizado, não deixa de ser um problema, pois o ser reconhecido está diretamente relacionado com fato que sustenta o que uma pessoa necessita para sentir-se importante e isto, nem sempre ocorre.

$\mathrm{Na}$ Psicologia, especialmente, na Psicologia Social, o interacionismo simbólico é 
tematizado pelo reconhecimento e discorre que, para o bem e crescimento interior do ser humano, a vida alterna entre períodos de altos e baixos, alegrias e tristezas, motivos pelos quais somos impelidos a levantar todos os dias com uma disposição inabalável para conquistar o mundo (CAILLÉ, 2010). O reconhecimento é o que distingue o ser humano dos demais e é também, uma conquista intuitiva obtida pela manifestação da força e de outras formas de dominação.

Prontamente, pensar sobre as interlocuções no processo de reconhecimento justifica a importância desta proposta de pesquisa, a qual almeja contribuir em conhecimentos para os estudos sobre o pensamento ético-político na Filosofia, permitindo a articulação do pensamento filosófico-psicológico com as práticas contemporâneas de busca pelo reconhecimento que, indubitavelmente, incluem o reconhecimento de grupos e minorias sociais, como as sociedades da América Latina e suas lutas por reconhecimento, contra as formas de desprezo nos processos de urbanização e migração dos povos latino-americanos e suas lutas por reconhecimento.

\section{CONCLUSÕES}

O caminho que possibilitou discorrer sobre a ideia da dimensão teórica acerca do reconhecimento dialoga com a fenomenologia, o existencialismo, a psicologia social, e psicanálise, em conjunto com o pensamento de Axel Honneth sobre o reconhecimento e sua contribuição para a sociedade contemporânea, cujo legado para os estudos do conhecimento filosófico e dos processos psicossocioculturais, tematiza aspectos psicológicos e de Teoria Crítica de imensurável alcance.

Diante dessas abordagens, os escritos de Hegel e Honneth são instrumentos postos que focalizam: (I) Os elementos conceituais sobre a teoria do reconhecimento; (2) Os elementos conceituais presentes que se introduzem na sociedade e na ciência contemporânea; (3) A identificação dos elementos conceituais em vários campos teóricos; (4) A reflexão sobre a organização da subjetividade e intersubjetividade presentes nos escritos de Hegel e de Honneth e; (5) A construção de um caminho reflexivo sobre a teoria do reconhecimento e o que torna uma pessoa feliz na contemporaneidade.

A leitura criteriosa das obras de Axel Honneth sobre a teoria do reconhecimento 
intencionou a compreensão da percepção deste autor quanto aos elementos conceituais presentes em seus escritos Hegel sobre a teoria do reconhecimento, identificando esses elementos que convergem e divergem de suas ideias na obra desse autor, não obstante, utilizando de estudos psicológicos e filosóficos que pensam sobre esta temática, provendo uma análise de conteúdo, que propõe a construção de um percurso reflexivo próprio de Axel Honneth. Logo, a primazia do objeto investigado foi propor uma reflexão sobre os modos de pensamento sobre o reconhecimento sob uma óptica estruturada na psicologia e na filosofia.

A discussão foi alicerçada nas obras de Axel Honneth. Luta por reconhecimento: A gramática moral dos conflitos sociais (2003) que possui diferentes versões, as quais diferem em conteúdo, após a ampliação dos estudos sobre o reconhecimento elaborados por Honneth, principalmente, entre a primeira versão e a segunda; O Direito à liberdade (2015); A ideia de Socialismo: Ensaio de atualização (2017), que é um estudo o qual propõe uma análise crítico reflexiva dos escritos de Axel Honneth.

Analisar a Teoria do Reconhecimento e suas possíveis contribuições para Filosofia, Psicologia e, ainda, para a Sociologia, esta última, mais especificamente para a Teoria Crítica permitiu focalizar a análise, a descrição e a interpretação dos conceitos e teorias do filósofo Axel Honneth e Friedrich Hegel, adentrando nas perspectivas sobre subjetividade filosófica, diferenciando-a da subjetividade psicológica e as questões que envolvem o processo de intersubjetividade quanto à problemática do reconhecimento na Filosofia que refetem sobre a capacidade e o poder do reconhecimento quanto ao tornar uma pessoa feliz, identificando as relações entre o reconhecimento e a felicidade no mundo da vida contemporânea.

Os conhecimentos sobre o tema reconhecimento nas teorias de Hegel e Axel Honneth pemitem diferenciar a subjetividade filosófica da psicológica e reflexionar sobre as questões da intersubjetividade na problemática do reconhecimento na Filosofia e na Psicologia, identificando as relações entre o reconhecimento e a felicidade.

Como recurso metodológico, presentifica-se a Fenomenologia de Martin Buber e do Espírito de Hegel estabelecendo um verdadeiro tratado sobre o reconhecimento que vem a defender conceitos como: moralidade, eticidade e da subjetividade, em conjunto a psicanálise lacaniana.

Por fim, a finalidade foi construir uma compreensão do reconhecimento por 
meio das ideias filosóficas, conceitos psicológicos e dos argumentos críticos que Honneth desenvolvem uma trajetória e um arcabouço argumentativo em torno da temática do reconhecimento e sobre o que torna uma pessoa feliz permitindo apresentar críticas às ideias de outros filósofos ao falar sobre o tema reconhecimento.

Conclui-se que a pela busca de felicidade relaciona-se com a autorrealização pessoal, a liberdade e autonomia em relação aos outros, no entanto, o reconhecimento não depende somente de nós mesmos para consigo mesmos. Ser reconhecido pelo outro, também, sustentaria a necessidade de suportes sociais. Hegel e Honneth solicitam uma concepção de autonomia social, subjetiva e intersubjetiva fundada no reconhecimento, onde a autonomia estaria atrelada à capacidade do indivíduo manter-se num contexto social de relações que se sustenta em conjunto ao sentimento intrínseco de ser autônomo e livre.

\section{REFERÊNCIAS}

BUBER, Martin. Eu e tu. $5^{\text {a }}$ edição. São Paulo: Centauro, 200 I.

CAILLÉ, Alain. Reconhecimento e sociologia. Revista brasileira de ciências sociais, 23 (66), I5I210, 2010.

HONNETH, Axel. A ideia de Socialismo. Lisboa: Edições 70, 2017. . O Direito à liberdade. São Paulo: Martins Fontes, 2015.

Editora 34, 2003. . Luta por reconhecimento: a gramática moral dos conflitos sociais. São Paulo:

HORKHEIMER, Max, ADORNO, Theodor W. Sociologia e Investigação Social Empírica. In: HORKHEIMER, Max, ADORNO Temas Básicos de Sociologia. São Paulo: Cultrix, [1956], 1978b. HORKHEIMER, Max. Teoria Crítica. São Paulo: Perspectiva: EDUSP, I99o.

HUSSERL, Edmund. A crise da humanidade europeia e a filosofia. Porto Alegre: Edipucrs, 2002.

LACAN, Jacques. Seminário XI: Os quatro conceitos fundamentais da psicanálise. Rio de Janeiro: Jorge Zahar Editora, I979.

MAINGUENEAU, Dominique. Discurso Literário. 2a edição. Trad. Adail Sobral. São Paulo: Editora Contexto, 2014.

MELO, Rurion. A teoria crítica de Axel Honneth. São Paulo: Saraiva, 2013. 
MENDONÇA, Ricardo Fabrino. Dimensão intersubjetiva da auto- realização: em defesa da teoria do reconhecimento. Rev. bras. Ci. Soc. vol.24 no 70 São Paulo, 2009. 